\section{Retinal light sensitivity in haemodialysis patients}

\begin{abstract}
Purpose The aim of the present study was to compare retinal light sensitivity between normal healthy subjects and chronic renal failure patients treated with maintenance haemodialysis (HD), as well as to determine whether there is a correlation between visual field loss and the age of HD patients, duration of HD treatment and hypertensive retinopathy in HD patients.

Methods A total of 50 eyes of $25 \mathrm{HD}$ patients (16 male, nine female) and 30 eyes of 15 controls underwent visual field testing on the $C$ 30-2 program of the Humphrey field analyser.

Results Significant reduction in retinal light sensitivity with mean deviation (MD)

$P$ values less than $5 \%$ was found in $36 \%$ (18 eyes), pattern standard deviation (PSD) $P$ values less than $5 \%$ in 16 eyes $(32 \%)$ and corrected pattern standard deviation (CPSD) $P$ values less than $5 \%$ in 16 eyes $(32 \%)$ of $\mathrm{HD}$ patients. In control group, all MD, PSD, and CPSD $P$ values were within normal limits. No correlation between reduction of retinal light sensitivity and age or duration of dialysis treatment was observed in HD patients. The reduction of retinal light sensitivity was significantly greater in HD patients with hypertensive retinopathy.

Conclusion In $36 \%$ of eyes from our HD patients without ophthalmoscopically evident arteriolar occlusion on fundus examination, a significant reduction in retinal light sensitivity was observed. The reduction was significantly greater in HD patients with hypertensive retinopathy.

Eye (2003) 17, 177-182. doi:10.1038/

sj.eye. 6700292
\end{abstract}

Keywords: retinal light sensitivity; haemodialysis; visual field; automated perimetry

D Pahor

\section{Introduction}

Ocular complications are frequent in patients with chronic renal failure treated with maintenance haemodialysis (HD), for example, renal retinopathy, exudative retinal detachment, cataract, increased intraocular pressure, band keratopathy, and calcium deposits in the conjunctiva and cornea. ${ }^{1-5}$ Many studies have demonstrated anterior and posterior segment abnormalities. ${ }^{1-14}$ Calcium deposits in the conjuctiva and cornea are frequent in HD patients. They occur in the interpalpebral region and are usually asymptomatic. ${ }^{3,4,7,12,15}$ Owing to improved dialytic techniques, a significant rise in intraocular pressure during HD rarely occurs anymore. ${ }^{2,13}$ On the posterior segment, retinal vascular abnormalities are frequently observed in HD patients. Signs of hypertensive retinopathy often occur in HD patients and may decrease with HD treatment and good hypertension control., ${ }^{44}$ Spontaneous retinal haemorrhages and optic neuropathy may also occur. ${ }^{4,8-10}$ Surgical problems in HD patients are well known. ${ }^{16}$ All these changes are mainly the results of the homeostatic breakdown of the body fluids. ${ }^{1}$

Retinal light sensitivity is an important measurable parameter of visual function. The introduction of automated static perimetry years ago has provided a new approach to the study of retinal function. Neuron loss may be detected at an earlier stage, which was not possible with manual perimetry. ${ }^{17-20}$ The presence, nature and the extent of retinal light sensitivity reduction were examined using automated static perimetry to detect visual field changes in our patients treated with HD.

The aim of the present study was to compare retinal light sensitivity between normal healthy subjects and chronic renal failure patients treated with maintenance HD, as well as to investigate whether there is a correlation
Department of Ophthalmology Teaching Hospital Maribor

Maribor 2000, Ljubljanska 5 Slovenia

Correspondence:

D Pahor

Tel: +38623211000

Fax: +38623312393

E-mail: d.pahor@sbmb.si

Received: 3 September 2001

Accepted in revised form: 15 May 2002 
between visual field loss and the age of the HD patients, duration of HD treatment and the degree of hypertensive retinopathy.

\section{Materials and methods}

All HD patients treated in the Department of Haemodialysis and satisfied the inclusion criteria were included in our study. At the end, 50 eyes of $25 \mathrm{HD}$ patients were included in the study. A control group (30 eyes of 15 subjects) was also enrolled. The controls underwent the same procedure. Efforts have been made to match the two groups in terms of age. Patients with diseases known to affect the visual field, such as aphakia, cataract, glaucoma, optic nerve, and macular disease and previous photocoagulation, were excluded from the study. Except for fundoscopic signs of hypertensive retinopathy, ophthalmologic examination was normal in all HD patients. The grading of hypertensive retinopathy is presented in Table 1. The exclusion criterion was the inability to perform visual field testing. Fixation was continually checked on the fixation monitor supplied on the Humphrey field analyser, which displayed the eye on a video screen during perimetry. The patients underwent complete ophthalmic examination, including visual acuity, slit-lamp examination, tonometry, ophthalmoscopy, and fundus photography. Patient's consent was obtained before recruitment into the study. Visual acuity was assessed with Snellen charts and was $20 / 25$ or more in all participants. Appropriate optical correction was worn during perimetric testing.

Automated visual field charting using threshold program C 30-2 of the Humphrey field analyser was performed on all participants. The Humphrey STATPAC analytic program was used to quantitatively evaluate each visual field. This program uses several global indices to compare the patient's visual field sensitivity with the age-corrected sensitivity of 76 points in a $30^{\circ}$ field. For this study three of the global indices, mean deviation (MD), pattern standard deviation (PSD) and corrected pattern standard deviation (CPSD), were used.

Table 1 Grading of hypertensive retinopathy

\begin{tabular}{|c|c|}
\hline Grade 1 & $\begin{array}{l}\text { Mild arteriolar attenuation, broadening of } \\
\text { arteriolar light reflex }\end{array}$ \\
\hline Grade 2 & $\begin{array}{l}\text { Severe arteriolar constriction associated } \\
\text { with deflection of veins at arteriovenous crossings }\end{array}$ \\
\hline Grade 3 & $\begin{array}{l}\text { Copper wiring of arterioles, banking and } \\
\text { tapering of veins, right-angled deflection of veins, } \\
\text { haemorrhages, cotton-wool spots, } \\
\text { hard exudates }\end{array}$ \\
\hline Grade 4 & $\begin{array}{l}\text { Changes of grade } 3 \text {, silver wiring of } \\
\text { arterioles, disc swelling }\end{array}$ \\
\hline
\end{tabular}

MD is the average elevation or depression of the patient's overall field compared with the normal age-corrected reference field. PSD is a measure of the extent to which the shape of the patient's measured visual field deviates from the normal, age-corrected reference field. CPSD is a measure of the degree to which the shape of the patient's hill of vision deviates from the normal age-corrected reference field after correction for the patient's intratest variability in response.

Demographic data were analysed. Analysis of variance (one-way ANOVA) was used to compare the MD, PSD, and CPSD between the two groups. Correlation test and $\chi^{2}$ test were used to find the association between age, duration of HD treatment, degree of hypertensive retinopathy, and visual field loss.

\section{Results}

The average age of our HD patients was 54.5 years ( \pm 10.5 ; min. 28, max. 69). Of the patients, 16 were male and nine female. The average duration of HD treatment was 4.9 years $( \pm 3.3$; $\min .1$, max. 12$)$. The average age of controls was 48.3 years $( \pm 17 ; \min .17$, max. 64$)$. Nine controls were male and six female.

Ophthalmological findings were normal for all participants in the control group whereas fundoscopic appearance was normal in only $10(20 \%)$ of the 50 eyes of HD patients. Grade I hypertensive retinopathy was evident in 16 eyes and grade II in the remaining 24 eyes of HD patients. No cases of severe hypertensive retinopathy (grade III or IV) were encountered.

We separately analysed the perimetric data for the right and the left eye in all HD patients. No statistically significant difference between MD, PSD, and CPSD values between both eyes was found. The same results were found in the control group. So for further analysis we did not separate the data between the right and the left eye (Table 2).

Of the 50 eyes, $18(36 \%)$ had obvious areas of reduced sensitivity on the greytone printout, with MD $P$ values

Table 2 Age, sex, and the presence of hypertensive retinopathy in our HD patinets and controls

\begin{tabular}{lcc}
\hline & $\begin{array}{c}\text { HD patients } \\
(50 \text { eyes })\end{array}$ & Controls (30 eyes) \\
\hline Average age (years) & $54.5( \pm 10.5)$ & $48.3( \pm 17)$ \\
Male & $16(64 \%)$ & $9(60 \%)$ \\
Female & $9(36 \%)$ & $6(40 \%)$ \\
Hypert. retinopathy & 40 eyes $(80 \%)$ & 0 \\
Grade I & 16 eyes $(32 \%)$ & 0 \\
Grade II & 4 eyes $(48 \%)$ & 0 \\
Grade III + IV & 0 & 0 \\
\hline
\end{tabular}


less than $5 \%$ (Figure 1). The average MD value was $-3.6 \mathrm{db}( \pm 3.5$; min. 0.2, max. -17.2$)$. In 16 eyes (32\%), PSD $P$ values of less than $5 \%$ were found. The average PSD value was $3.8 \mathrm{db}( \pm 2.6$; $\min$. 1.4, max. 12.4). CPSD $P$ values of less than $5 \%$ were also observed in 16 eyes $(32 \%)$. The average CPSD value was $2.7 \mathrm{db}( \pm 2.8$; min. 0, max. 11.2). In the control group, normal retinal light sensitivity was found (Table 3 ).

The indices of visual field sensitivity (MD, PSD, CPSD) have been evaluated for both groups, HD patients and controls. The difference in the MD value between HD patients and controls in central visual field was significant $(P<0.004)$. The same results were also found for PSD $(P<0.005)$ and CPSD $(P<0.007)$ values (Table 4$)$.

The age of our HD patients and the duration of HD treatment were not associated with the reduction of retinal light sensitivity regarding the MD, PSD, and CPSD values $(P>0.10)$.

The reduction of retinal light sensitivity was associated with the degree of hypertensive retinopathy. From 40 eyes with hypertensive retinopathy of grade I and II together, 17 eyes $(42.5 \%)$ had MD $P$ values less than 5\%, 14 eyes (35\%) PSD $P$ values less than $5 \%$ and 16 eyes (40\%) CPSD $P$ values less than 5\%. In 10 eyes without hypertensive retinopathy, only in one eye $(10 \%)$ were MD and in two eyes PSD $P$ values less than $5 \%$. In eyes without hypertensive retinopathy, no CPSD $P$ value was less than $5 \%$. The difference between HD patients with or without hypertensive retinopathy was significant $(P<0.0001)$ (see Table 5).

\section{Discussion}

Significant reduction in retinal sensitivity in the central visual field was observed with MD $P$ value less than 5\% in 18 from 50 eyes (36\%) of our HD patients.

The mean age of HD group is 6 years greater than that of the controls. This age disparity is of no consequence since the main study data for each individual tested rely on global indices that are based on comparision with agecorrected normative data. There were no differences in the transparency of the ocular media in the older patient group. All HD patients with lens and corneal opacities associated with or without maintenance HD were excluded from the study.

The majority of the patients have arterial hypertension before starting HD treatment. After starting with maintenance HD, the hypertension is usually more or less regulated with or without therapy. ${ }^{4}$ Some patients remain hypertensive because of hypereninaemia. In most cases, routine antihypertensive drug therapy is effective. ${ }^{4}$ This is the reason why $80 \%$ of our HD patients have hypertensive retinopathy of grade I or II, and may be the reason why we did not observe a severe hypertensive retinopathy in our HD patients. Unfortunately, no exact data on duration of hypertension prior to HD treatment were obtained, so we could not compare the influence of hypertension duration on visual field loss in our HD patients. No typical type of field loss was observed. We found no similar pattern or location of visual field defects between our HD patients.

It is well known that in hypertensive retinopathy of grade I and II, the attenuation and constriction of retinal arterioles are noted without arterial occlusion. The cotton-wool spots, which are the results of arteriolar occlusion, are characteristic of grade III and IV. In our HD patients, no fundoscopic signs of arteriolar occlusion were seen. Despite these findings, the reduction of sensitivity was observed in more than a third of our HD patients. Some investigators found that cotton-wool spots are associated with localised scotoma in visual field, which may persist or disappear in the phase of resolving of cotton-wool spots over time. ${ }^{21-23}$ We found no publications on visual field loss in hypertensive patients. Unfortunately, fluorescein angiography was not performed in our HD patients. Visual field defects can be detected prior to visible retinal damage. The investigation of retinal sensitivity following blunt ocular trauma without visible fundoscopic abnormality confirms this hypothesis. ${ }^{24,25}$ Visual field loss in HD patients without evident posterior segment abnormality of arteriolar occlusion could be primarily the result of disturbed retinal circulation.

In 1998, Gandolfo et $a^{26}$ first described the perimetric changes in carotid obstructive disease as a consequence of a subclinical chronic ischaemic retinopathy. They concluded that the most important factor for visual field loss is probably the chronic ischaemic damage to the retinal nerve fibres because of increased red cell aggregation, decreased red cell deformity and increased viscosity.

HD patients have advanced atherosclerosis in carotid arteries compared with age- and sex-matched control subjects. $^{27}$ The intima-media thicknesses of the common carotid and internal carotid arteries were higher in HD patients compared with controls. There was a positive correlation with age, but not with duration of HD treatment. ${ }^{28}$ The causes for these complications are hypertension, hyperlipidaemia, glucose intolerance, chronic high cardiac output, metastatic vascular and myocardial calcification. ${ }^{27}$

Perimetric defects were present in $36 \%$ of our HD patients; this suggests the existence of a subclinical chronic ischaemic retinopathy which could be detected with automated perimetry. There are other tests like electophysiology which are also useful for these studies. We concluded that these may be because of subclinical ischaemic retinopathy as a consequence of carotid 
SINGLE FIELD ANALYSIS

NAME $: Z \quad T$ ID

CENTRAL 3Q-2 THRESHOLO TEST

FIXATION MONITOR: GAZE/BLINDSPOT

FIXATION TARGET: CENTRAL

FIXATION LOSSES: $1 / 28$

FALSE POS ERRORS: $\theta / 19$

FALSE NEG ERRORS: $1 / 17$

TEST DURATION: $19: 29$

FOVEA: OFF
STIMULUS: III, LHITE

BACKCROUND: 31.5 ASB

STRATEGY: FULL THRESHOLD
PUPIL DIAMETER: $4.3 \mathrm{MH}$

UISUAL ACUITY:

$R X:+4.25$ DS OC $X$
DRTE: $86-04-2000$

TIME: $13: 39$

AGE: 66
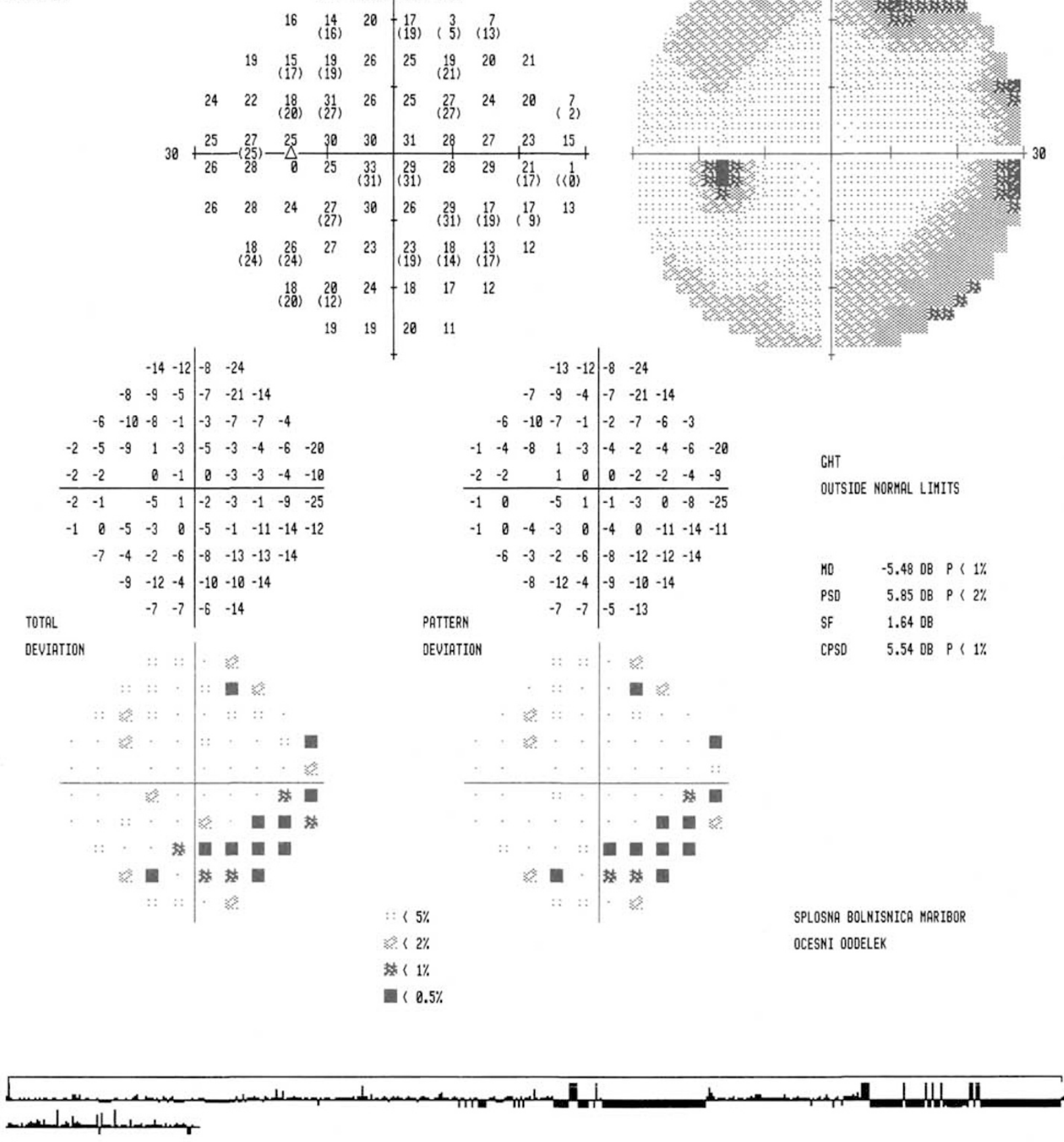

Figure 1 Visual field loss in our HD patient with hypertensive retinopathy of grade II. 
Table 3 Reduction in retinal light sensitivity in our HD patients

\begin{tabular}{lcc}
\hline & HD patients (50 eyes) & Controls (30 eyes) \\
\hline $\mathrm{MD}<5 \%$ & 18 eyes (36\%) & 0 \\
$\mathrm{PSD}<5 \%$ & 16 eyes $(32 \%)$ & 0 \\
$\mathrm{CPSD}<5 \%$ & 16 eyes (32\%) & 0 \\
\hline
\end{tabular}

Table 4 Comparision of retinal light sensitivity in central visual field between HD patients and controls

\begin{tabular}{lccc}
\hline & HD patients & Controls & $p$ value \\
\hline MD $(\mathrm{db})$ & -3.64 & -0.89 & $<0.004$ \\
PSD $(\mathrm{db})$ & 3.78 & 1.82 & $<0.0053$ \\
CPSD $(\mathrm{db})$ & 2.72 & 0.72 & $<0.0073$ \\
\hline
\end{tabular}

Table 5 Reduction in retinal light sensitivity in eyes with and without hypertensive retinopathy in our HD patients

\begin{tabular}{lll}
\hline & \multicolumn{2}{c}{ HD patients (50 eyes) } \\
\cline { 2 - 3 } & $\begin{array}{c}\text { With hypertensive } \\
\text { retinopathy }\end{array}$ & $\begin{array}{c}\text { Without hypertensive } \\
\text { retinopathy }\end{array}$ \\
\hline $\mathrm{MD}<5 \%$ & 17 eyes $(42.5 \%)$ & 1 eye $(10 \%)$ \\
$\mathrm{PSD}<5 \%$ & 14 eyes $(35 \%)$ & 2 eyes $(20 \%)$ \\
CPSD $<5 \%$ & 16 eyes $(40 \%)$ & 0 \\
\hline
\end{tabular}

obstructive disease in HD patients and in association with hypertensive retinopathy.

To our knowledge, this study is the first to assess retinal light sensitivity in HD patients using automated perimetry. A further prospective study with ultrasound measurements of the intima-media thickness in the carotid artery and retinal angiography are necessary to confirm our results.

In conclusion, in $36 \%$ of eyes in our HD patients without evident arteriolar oclusion on fundus examination, a significant reduction of retinal light sensitivity was observed. In eyes with hypertensive retinopathy, the reduction in sensitivity was much more pronounced.

\section{References}

1 Ohguro N, Matsuda M, Fukuda M. Corneal endothelial changes in patients with chronic renal failure. Am J Ophthalmol 1999; 128: 234-236.

2 Hojs R, Pahor D. Intraocular pressure in chronic renal failure patients treated with maintenance hemodialysis. Ophthalmogica 1997; 211: 325-326.
3 Pahor D, Hojs R, Gračner B. Conjunctival and corneal changes in chronic renal failure patients treated with maintenance hemodialysis. Ophthalmologica 1995; 209: 14-16.

4 Polak BCP. Ophthalmological complications associated with hemodialysis. In: Maher JF (ed). Replacement of Renal Function by Dialysis: A Textbook of Dialysis. Kluwer Academic Publisher: Dordrecht, 1989, pp 987-991.

5 Tomazzoli L, De-Natale R, Lupo A, Parolini B. Visual acuity disturbances in chronic renal failure. Ophthalmologica 2000; 214(6): 403-405

6 Stein G, Strobel J. Augenveränderungen bei Patienten mit chronischer Niereninsuffizienz und Hämodialysepatienten Nieren Hochdruck 1994; 23: 309-314.

7 Pahor D, Hojs R, Gračner B. Hornhaut- und Bindehautveränderungen bei hämodialysierten Patienten. Spektrum Augenheilkunde 1998; 12(1): 16-18.

8 Jackson TL, Farmer CK, Kingswood C, Vickers S. Hypotensive ischemic optic neuropathy and peritoneal dialysis. Am J Ophthalmol 1999; 128: 109-111.

9 Haider S, Astbury NJ, Hamilton DV. Optic neuropathy in uraemic patients on dialysis. Eye 1993; 7: 148-151.

10 Knox DL, Hanneken AM, Hollows FC, Miller NR, Schick Jr HL, Gonzales WL. Uraemic optic neuropathy. Arch Ophthalmol 1988; 106: 50-54.

11 Hamed LM, Winward KE, Glaser JS, Schatz NJ. Optic neuropathy in uraemia. Am J Ophthalmol 1989; 108: 30-35.

12 Klaassen-Broekema N, van Bijsterveld OP. Limbal and corneal calcification in patients with chronic renal failure. $\mathrm{Br}$ I Ophthalmol 1993; 77: 569-571.

13 Zagelbaum BM, Tostanoski JR, Kremer DJ, Hursh PS, Gafter $\mathrm{U}$, Pinkas $\mathrm{M}$ et al. Intraocular pressure in uremic patients on chronic hemodialysis. Nephron 1985; 40: 74-75.

14 Das T, Gupta A, Sakhuja V, Gupta KL, Minz M, Chugh KS Ocular complications in renal allografts recipients. Nephrol Dial Transplant 1991; 6: 649-655.

15 Jarava C, Marti V, Gurpegiu ML, Merello JI, Rdez-Quesada B, Palma A. Pulmonary calcification in chronic dialysis patients. Nephrol Dial Transplant 1993; 8: 673-674.

16 Lawton RL, Gulesserian HP, Rossi NP. Surgical problems in patients on maintenance dialysis. Arch Surg 1968; 97: 283-289.

17 MJ Haley (ed). Statpac Users Guide. Allergan Humphrey: San Leandro, CA, 1986.

18 Anderson DR. Automated Static Perimetry, Mosby-Year Book: St Louis, MO, 1992.

19 Stewart WC. Avoiding mistakes in interpreting visual fields. I. Basic concepts. Clin Signs Ophthalmol 1993; 14(3): 2-15.

20 Stewart WC. Avoiding mistakes in interpreting visual fields. II. Evaluating the printout. Clin Signs Ophthalmol 1993; 14(4): 2-15.

21 Pahor D. Automated static perimetry as a screening method for evaluation or retinal perfusion in diabetic retinopathy. Int Ophthalmol 1998; 21: 305-309.

22 Bek T, Lund-Anderson H. Localized blood-retinal barrier leakage and retinal light sensitivity in diabetic retinopathy. Br J Ophthalmol 1990; 74: 388-392.

23 Chee CK, Flanagan DW. Visual field loss with capillary nonperfusion in preproliferative and early proliferative diabetic retinopathy. Br J Ophthalmol 1993; 77: 726-730.

24 Pahor D, Gračner B. Visual field loss following blunt ocular trauma. Ophthalmologica 1998; 212: 43-45. 
25 Pahor D. Changes in retinal light sensitivity following blunt ocular trauma. Eye 2000; 14: 583-589.

26 Gandolfo E, Corallo G, Ottonello G et al. Perimetric findings in carotid obstructive disease. Neuro-ophthalmology 1998; 19(4): 191-203.
27 Brenner BM, Lazarus JM. Chronic renal failure. In: Wilson JD (ed). Harisson's Principles of Internal Medicine. McGrawHill: New York, 1991, pp 1150-1156.

28 Hojs R. Carotid intima-media thickness and plaques in hemodialysis patients. Artif Organs 2000; 24(9): 691-695. 